\title{
OS FLUXOS EDUCATIVOS DE FRANTZ FANON
}

Fernando Santos de Jesus*

\begin{abstract}
Resumo: Este artigo tem por objetivo analisar as obras de Frantz Fanon a partir do viés educativo, entendendo que suas contribuições epistemológicas confluem para o campo da educação. Partimos do princípio de que Fanon, ao empreender um conjunto de possibilidades sobre as causas dos traumas da colonização, traz no bojo de suas teses um princípio educativo para a descolonização dos sistemas oficiais de ensino.
\end{abstract}

Palavras-chave: Descolonização; Epistemologia; Educação; Trauma; Colonização.

Resumen: Este artículo tiene por objetivo analizar las obras de Frantz Fanon a partir de un sesgo educativo, entendiendo que sus contribuciones epistemológicas confluyen, precisamente, hacia este campo. Partimos del principio de que Fanon, al emprender un conjunto de posibilidades sobre las causas de los traumas de la colonización, coloca en el seno de sus tesis un principio educativo para la descolonización de los sistemas oficiales de enseñanza.

Palabras clave: Descolonización; Epistemología; Educación; Trauma; Colonización.

\section{Quem foi Frantz Fanon?}

Martinicano, nascido no ano de 1925, o psiquiatra Frantz Fanon foi um estudioso do colonialismo francês nas Antilhas e na África francófona; seus esforços visavam analisar os traumas e neuroses adquiridos pelos colonizados durante o regime colonial nestes territórios. Fanon escolheu como campo de análise os efeitos psicológicos causados por um processo violento de alienação de si, a partir da massificação de valores exógenos aos autóctones. Desse modo, ele perseguiu a compreensão dos mecanismos de dominação, tendo como ferramentas de estudo, a linguagem, o estereótipo (por meio da hiperssexualização dos corpos negros) e as políticas institucionais, categorias analíticas que potencializam e tornam

\footnotetext{
* Doutorando do Programa de Pós-Graduação em Educação da Universidade Federal do Ceará - UFC, Bolsista do Conselho Nacional de Desenvolvimento Científico e Tecnológico - CNPq. fernandosenzala@hotmail.com
}

perene o racismo anti-negro. A partir desses olhares, Fanon acreditava que seria possível propor um combate sistemático contra o racismo nos sistemas coloniais.

No ano de 1950, Fanon defende sua tese sobre os efeitos psíquicos do racismo no sistema colonial, sendo rejeitada pela universidade de Lyon, na França, o que acarretou na necessidade de transformação do texto, que passou a se chamar: "Troubles mentaux et syndromes psychiatriques dans l'hérédo-dégénération-spino-cérébelleuse: Um cas de maladie de Friereich avec délire de possession”, e só assim obteve a titulação do doutorado. Cabe observar que sua primeira tese foi revisada, por ele mesmo, e lançada posteriormente com outro título: "Peau noir, masques blancs".

Foi durante este período que Fanon se debruçou sobre as análises daquilo que observava cotidianamente no trânsito entre a metrópole (França) e a colônia (Martinica), chegando à conclusão de que seria ne-

JESUS, Fernando Santos de. Os fluxos educativos de Frantz Fanon. Revista Sul-Americana de Filosofia e Educação. Número 30: nov./2018-abr.2019, p. 64-74. DOI: https://doi.org/10.26512/resafe.vi3o.28242 
cessário empreender um estudo não somente acerca do colonizado negro, mas também sobre o comportamento do colonizador branco, pois somente entendendo os traumas psicológicos da branquitude, seria possível compreender o ressentimento branco projetado sobre os negros - eis o salto qualitativo do pensamento de Fanon, causa do incômodo institucional branco, culminando na reprovação de sua tese ${ }^{2}$.

Consolidado como brilhante psiquiatra, Frantz Fanon decidiu se lançar na luta anticolonial, estando à frente do processo de libertação argelina, onde foi chefe do setor de psiquiatria no hospital BlidaJoinvile, em 1953. Durante o período de luta anticolonial naquele país, Fanon trabalhou no órgão central da imprensa revolucionária, o jornal El Moudjahid, para qual redigiu diversos textos, nos? quais analisava o processo de colonização dos países africanos e quais as melhores estratégias de luta anticolonial. Esse conjunto de textos são, posteriormente, reunidos e transformados em um livro, com o título: "Em Defesa da Revolução Africana”, lançado em Portugal, no ano de 1980, pela Livraria Sá da Costa Editora.

A grandeza do pensamento de Frantz Fanon não se esgota nesta pequena introdução, mas está materializada em: Pele Ne-

\footnotetext{
${ }^{2}$ Cabe lembrar que o sociólogo brasileiro Guerreiro Ramos (1915-1982) dedica um capítulo do seu livro "Introdução Crítica a Sociologia Brasileira" a analisar a tematização da população negra, pelos pesquisadores brancos. Segundo ele esses intelectuais são grandes responsáveis por massificar estereótipos acerca dos negros na sociedade brasileira, pois são atualizadores de teorias estrangeiras que nada têm a ver com a realidade nacional, agindo em conformidade com um negro idealizado - negativamente -, sem que haja real aproximação com o negro vivencial. O capítulo se chama "Negro Tema".
}

gra, Máscaras Brancas (1952); L’an V de la Révolution Algérienne (1959); Os Condenados da Terra (1961) e Pela Revolução Africana (1964). Estas obras foram revisadas e traduzidas para vários idiomas, e hoje constituem importante vetor para compreensão dos efeitos psicológicos causados pelos dispositivos colonialistas, responsáveis por forjar uma ambiência negativa para as populações não ocidentais, normatizando o racismo institucional, transformado em linha de frente que confere privilégios às populações brancas nos territórios que atravessaram experiências coloniais³.

\section{Por uma Educação não Colonial}

Frantz Fanon nada escreveu sobre sistemas e métodos para educação formal. Sua literatura esteve voltada para a busca da compreensão sobre os caminhos percorridos pelo processo de colonização dos países africanos e da diáspora negra nas américas, pensando as possíveis saídas desses sistemas. Estas análises foram feitas à luz de teorias filosóficas e do campo da psicologia, atravessadas pelo viés racial e carregando em si uma ambiência provocativa, que produz uma atmosfera pedagógica. O tom propositivo com que Fanon encadeia suas teses sinaliza para a possibilidade de reorganiza-

\footnotetext{
3 Importante sublinhar que Fanon inaugura uma frente de pesquisas que hoje se intensifica com grupos de intelectuais chamados decoloniais, dentre os mais famosos estão: o filósofo argentino Enrique Dussel, o sociólogo peruano Aníbal Quijano, o semiólogo argentino Walter Mignolo, o sociólogo porto-riquenho Ramón Grosfoguel, a linguista norteamericana radicada no Equador Catherine Walsh, o filósofo porto-riquenho Nelson Maldonado-Torres e o antropólogo colombiano Arturo Escobar.
} 
ção do olhar em torno dos sistemas disciplinares que interpelam o colonizado.

As críticas as quais este pensador defere para os sistemas coloniais orbitam em torno das necessidades de compreensão da psicologia do colonizado. Fanon direciona boa parte de suas teses a questionar os efeitos de um processo colonial secular, que, potencializado e massificado no cotidiano das relações sociais, tende a gerar uma internalização de valores exógenos aos construídos pelas regras comunitárias dos sistemas culturais pré-coloniais. Para Fanon esse foi um processo violento e adoecedor.

$\mathrm{O}$ malgaxe não existe mais. $\mathrm{O}$ malgaxe existe com o europeu. O branco, chegando a Madagascar, tumultuou os horizontes e os mecanismos psicológicos. Todo mundo já o disse, para o negro a alteridade não é o outro negro, é o branco. Uma ilha como Madagascar, invadida de um dia para o outro pelos "pioneiros da civilização", mesmo que esses pioneiros tenham se comportado da melhor maneira possível, sofreu uma desestruturação (FANON, 2008 p.93).

Fica evidente, portanto, que a não contenção dos fluxos da subjetividade, transformaria qualquer relação na imanência dos encontros de diferentes perspectivas vivenciais. Isso não é, entretanto, afirmar que produção de diferença só seria possível a partir desses contatos, mas, sim, sugerir que a diferença que emerge dessas afetações inaugura uma nova produção de diferença, agora orientada por novos mecanismos que fabricam ficções, organizando o ethos e condicionando os comportamentos aos ajustes morais verticalmente construídos.
O ponto chave para pensar as obras de Fanon, vem por meio dos seguintes questionamentos: A solução mais viável para o colonizado se liberar das amarras do colonialismo seria criar roeduras por dentro do próprio sistema colonial através das instituições? Ou, por meio de uma ruptura radical que expurga os valores coloniais dos seus esquemas mentais e imanentes (do seu solo), "resgatando" uma cultura ancestral que remonta os períodos nos quais seria possível viver sem os axiomas trazidos pelos invasores alienígenas?

O pensamento de Fanon não se enquadra sistematicamente nas possibilidades apresentadas, uma vez que, embora sugerisse um processo clínico de "descolonização das mentalidades", o autor não se furtava do fato da impossibilidade de um completo apagamento daquilo que foi absorvido a partir do ethos massificado pelos sistemas de poder disciplinares que agem por dentro da ambiência colonial. Apesar desse fato, Fanon dava credibilidade ao saber rizomático, isto é, a construção de conhecimentos a partir de complexas teias de relações, as quais não necessitam de estágios de superação de fases anteriores, como pressupõe o método dialético. Essa leitura pode ser feita a partir das obras: "Os Condenados da Terra" (1961) e "Pele Negra, Máscaras Brancas" (2008).

Esse é um ponto indispensável para pensar a possibilidade de um fluxo educativo revolucionário, proposto por Frantz Fanon. O apagamento total daquilo que foi massificado no espírito do colonizado seria impossível, uma vez que é através da duração da conservação de traços na memória, que o colonizado conseguiria ressignificar e 
reinventar sua própria história. Essa não é uma atividade completamente racional e propositiva. Sugerimos que o leitor tome contato com a obra de Henry Bergson: "A Evolução Criadora”.

Segundo Deleuze e Guattari (2014), o rizoma se faz por meio da memória curta, justamente por apresentar uma rede de interfaces que se relacionam sem arborescência, ou seja, sem que haja um circuito que retorne a origem de um fenômeno, pressupondo a necessidade de superação de estágios subsequentes para acontecer. Nesse sentido, a conservação de uma memória longa dificultaria um rizoma que, no entanto, acontece com pontos de arborescência. É como um armário de várias gavetas que são desmembradas e utilizadas para outras funções, se colocadas no móvel, será um armário com gavetas, mas se desmembradas, serão as gavetas de um armário (BERGSON, 2014).

Frantz Fanon não se prende a um padrão que tenha a necessidade de resgate histórico e filosófico messiânico e romantizado; ao contrário, ele propõe uma justa medida para o colonizado. A proposição apresentada é a de que pavimentar um caminho rumo à emancipação colonial pressupõe negociações e tensionamentos, uma vez que os sistemas se reorganizam em seus limites, isto é, as máquinas despóticas encontram no limite do esgotamento dos modelos dominantes uma maneira de capturar tudo aquilo que se apresente como ruptura do modelo que se desgasta (Deleuze e Guattari, 2010). Ao fazer isso, o sistema reabsorve os residuais sociais sob nova forma, oxigenando as engrenagens institucionais, fazendo com que funcionem novamente até novas organizações serem criadas e, no limite, reabsorvidas.

Ao compreender que as máquinas despóticas se refazem no limite, o colonizado passa a operar por micropolíticas rizomáticas, numa espécie de "catação" 4 . Esse deslizar do colonizado, é um aprendizado transdisciplinar, que rejeita o decalque disciplinar arbóreo sugerido pelos sistemas de poder colonial. Os saberes que se agrupam e se tangenciam, possibilitam olhares diversos sobre a realidade que os rodeia, e isso só pode ser feito a partir da abertura para vivências de várias ordens - no aumento do repertório -, não deixando de lado os pontos de arborescência, tendo em vista que a memória salvaguarda os traços necessários para que os processos educativos se firmem no espírito, desenvolvendo a capacidade criativa de articulação holística entre vários elementos.

Desse modo, Fanon não propunha o resgate ancestral de uma história sem movimento e disjuntiva, pois pensar dessa maneira o classificaria com adepto a uma filosofia eurocêntrica das essências eternas, análoga a do século XVIII e até boa parte do XIX, que negava historicidade aos negros e indígenas, como justificativa de retirar-lhes a humanidade. Desse modo, eliminando o tempo de realização da cultura negra, esses filósofos aprisionavam os negros africanos a

\footnotetext{
$4 \mathrm{O}$ catador pode ser um personagem conceitual (Deleuze e Guattari, 2010) que desliza sobre o plano superficial da imanência, criando linhas de fuga a partir das relações fluídas e dinâmicas, operando por meio de redes de contato que o faz aglutinar saberes que serão a base de processos criativos que lhes permitirá mobilidade sobre o plano. Este é um personagem rizomático, que faz da superficialidade sua própria profundidade.
} 
um lugar remoto e sem devir, e se esses povos não acontecem, logo estariam em um nível de desenvolvimento humano inferior ao dos europeus. Fanon seria, portanto, radicalmente contrário a qualquer modo de prescrição de normas de condutas morais para os negros, mesmo pelos próprios negros, já que o aprisionamento dos desejos, deslocados do sentido ético de preservação da espécie humana, ameaçaria o devir do próprio negro5 ${ }^{5}$.

O fluxo educativo que podemos esquadrinhar a partir dos olhares de Frantz Fanon, ultrapassa o próprio sentido revolucionário que está por dentro da rotineira qualificação do referido conceito, o de revolução. Não se empreende profundas transformações sociais a partir de inclinações homogêneas, aglutinadas por princípios de moralidade que retornam para objetivos localizados e hierarquizados, pois esta perspectiva abre as portas para o aprisionamento sistêmico sugerido pelas soberanias disfarçadas de "democracia". Justamente por esse motivo, que Frantz Fanon empreendeu a luta anticolonial, só que em uma esfera posta para além das libertações nacionais tuteladas por sistemas gestados no cerne

\footnotetext{
5 A esse respeito se torna incontornável o conhecimento do postulado ético proposto pela filosofia Ubuntu, ilustrado pelo aforisma "Motho Ke Motho Ka Batho” (RAMOSE, 2010), que conduz ao princípio existencial a partir do sentimento partilhado de pertença, não localizado em torno de grupos minoritários fechados em si. Desse modo, a filosofia Ubuntu diz respeito aos agenciamentos minoritários que fortalecem os grupos não dominantes para o ingresso na universalidade, indispensável para o firmamento humanitário de mútua cooperação, onde as diferenças existam por si só, enfraquecendo, ou eliminando, portanto, os ordenamentos sistêmicos das hierarquias construídas por sistemas que institucionalizaram o ressentimento.
}

das metrópoles, uma vez que esses ordenamentos, em seus limites, retornariam a atrozes arrochos contra o colonizado.

Todo colonizado que aceita hoje um lugar governamental deve saber claramente que terá de caucionar, mais tarde ou mais cedo, uma política de repressão, de massacres, de assassinatos coletivos, numa das regiões do "Império francês" (FANON, 1980, p.142).

Podemos então dizer que Frantz Fanon estaria chamando a atenção para a préfabricação de soluções para problemas inventados. Dito de outro modo, se as premissas prescritas pelo colonialismo forem introjetadas pelo colonizado, mesmo suas linhas de fuga, ou busca de soluções para momentos de crise, retornarão sob nova capa, em um processo cíclico de gestão da servidão, na qual o colonizado se mantém dependente dos mandatários do colonizador, ou das máquinas do colonialismo.

Nesse sentido, fica evidente a necessidade de uma nova pedagogia, na qual os valores ocidentais não sejam os orientadores normativos, mas que também não seja algo fabricado em resposta ao eurocentrismo, isto é, Fanon rejeita a sobredeterminação, e faz isso em nome de fluxos que se (re)constroem para além de qualquer força reativa - eis que surge o conceito de homem novo. Pôr de pé um homem novo é não estar sorvido por sistemas que aprisionam os desejos, produzindo sentidos mecânicos e dependentes de necessidades administradas pela oferta de (sub)produtos que encaixota o espírito. Diante desta lógica, até mesmo a transgressão não passa de um espectro, fóssil congelado aos mandatários de 
uma centralidade que comprime as diferenças.

Portanto, camaradas, não paguemos tributos a Europa criando estados, instituições e sociedades que nela se inspirem. A Humanidade espera de nós uma coisa bem diferente dessa imitação caricatural e, no conjunto, obscena. Se desejamos transformar a África numa nova Europa, a América numa nova Europa, então confiemos ao europeu o destino de nosso país. Eles saberão fazê-lo melhor do que os mais bemdotados entre nós. Mas se queremos que a humanidade avance, se queremos levar a humanidade a um nível diferente daquele onde a Europa a expôs, então temos de inventar, temos de descobrir. Se queremos corresponder à expectativa dos europeus, não devemos devolver-lhes uma imagem, mesmo ideal, de sua sociedade e de seu pensamento, pelos quais eles experimentam de vez em quando uma imensa náusea. Pela Europa, por nós mesmos e pela humanidade, camaradas, temos de mudar de procedimento, desenvolver um pensamento novo, tentar colocar de pé um homem novo. (FANON, 1961, p.274-275).

Observa-se que Fanon reconhece que o nível de colonização ao qual o mundo foi compelido, torna inviável não admitir que o ethos europeu organizou as relações locais, a ponto de transformar brutalmente esses colonizados em superdependentes quando precisam operar pensamento filosófico, buscando o seu ponto de partida na imagem ocidental. Desse modo, existe uma duplicidade nas linhas de fuga adotadas como estratégias de luta anticolonialista. Se por um lado existe positividade nos esforços em resgatar elementos, ou rudimentos, filosóficos omitidos pelo poder colonial - através do epistemicídio ${ }^{6}$ impingido às populações autóctones -, por outro, esses aforismas não podem vir à tona como respostas ao sistema mundo ocidentalizado, pois isso recairia na disputa binária por legitimidade, que, em última instância, só pode ser dada por aqueles que detém o poder discursivo de conceituação.

Existe a possibilidade de conceber o pensamento de Frantz Fanon enquanto centrista, pois sua pedagogia é a da autoctonia, na imanência do território colonizado que precisa ser desterritorializado em seu próprio solo, produzindo, com efeito, a reterritorialização do mesmo diferente. Grosso modo, o centro dos acontecimentos que alienam os autóctones é o seu próprio território, após o processo de colonização.

Desterritorializar o sofrimento colonial seria reorganizar o solo, e a si mesmo, repensando os valores coloniais empurrados violentamente pelo exercício do poder bélico e pelo enquadramento das subjetividades, viabilizados pela institucionalização da vida. Reterritorializar, portanto, o autóctone, é dar vida a um homem novo, um ser humano gerado no útero de uma sociedade onde não se busque nos traumas da colonização as respostas necessárias para um novo modelo de vida, e a memória curta possibi-

\footnotetext{
${ }^{6}$ Sobre epistemicídio podemos conceber que seja a invisibilização e o furto de modos autóctones de construir conhecimento. O epistemicídio se materializa na distorção e no apagamento histórico, em relação à autenticidade de pensamento não dominante, passando ao estágio seguinte, que é a desapropriação do que se cria por grupos minoritários. A respeito disso ver RAMOSE, Mogobe. Sobre a Legitimidade e o Estudo da Filosofia Africana. Ensaios Filosóficos, Volume IV - Outubro/2011.
} 
lite o surgimento de novas narrativas. Devolver o lugar do autóctone não pressupõe, entretanto, uma genealogia fechada, e sim um estado dinâmico de fluxos criativos, no qual o passado não se institua como plenitude idealizada, um ente acabado, sem movimento e sem diálogo com a situação atual em que se encontra o povo local.

Não quero, acima de tudo, ser mal compreendido. Estou convencido de que há grande interesse em entrar em contato com uma literatura ou uma arquitetura do século III a.C. Ficaríamos muito felizes em saber que existe uma correspondência entre tal filósofo preto e Platão. Mas não vemos, absolutamente, em que este fato poderia mudar a situação dos meninos de oito anos que trabalham nas plantações de cana da Martinica ou de Guadalupe. Não se deve tentar fixar o homem, pois o seu destino é ser solto. A densidade da história não determina nenhum de meus atos. Eu sou meu próprio fundamento. É superando o dado histórico, instrumental, que introduzo o ciclo de minha liberdade. A desgraça do homem de cor é ter sido escravizado. A desgraça e a desumanidade do branco consistem em ter matado o homem em algum lugar. Consiste, ainda hoje, em organizar racionalmente essa desumanização. Mas, eu, homem de cor, na medida em que me é possível existir absolutamente, não tenho o direito em me enquadrar em um mundo de reparações retroativas. $\mathrm{Eu}$, homem de cor, só quero uma coisa: Que jamais o instrumento domine o homem, que cesse para sempre a servidão do homem pelo homem. Ou seja, de mim por outro. Que me seja permitido descobrir e querer bem ao homem, onde quer que ele se encontre. $\mathrm{O}$ preto não é.
Não mais que o branco (FANON, 2008 P.190-191).

Fica evidente, portanto, que Frantz Fanon empreendia seus esforços para pensar novas relações, e que esse homem novo se ponha de pé sem a conservação de tipologias que dão vida ao ressentimento ${ }^{7}$. Por esse motivo, Fanon insistia no fato de que a busca por resgatar um histórico cultural cada vez mais pré-colonial possível, constituiria um nível necessário, porém não determinante para a construção de uma nova cidadania. A mobilização política e identitária, por meio de novos olhares sobre a história dos colonizados, serviria para dar-lhes autenticidade e autodeterminação filosófica, fortalecendo o sentimento de pertencimento ao solo autóctone, dispensando o determinismo que provém da situação colonial.

Entretanto, Fanon deixa nítido que esta mobilização não pode ser reativa, ou seja, não pode constituir motivo de revanchismo e busca por inversão de dominação, nem tampouco uma adoção inconteste ao ethos colonizador. Operar vinganças contra o mundo colonial é viver sob a égide do espectro da opressão, que encarna cotidianamente, pelos aparelhos de dominação, o

\footnotetext{
7 Aqui é importante realçar que a questão topológica do ressentimento se dá pela conservação de traços que se transferem do campo da ficção para o vivencial, possibilitando a insurgência das forças reativas para o plano ativo. Para tanto, essas transferências de potências se concentram em tipos, ou seja, "essa definição topológica deve introduzir-nos a uma "tipologia" do ressentimento, pois quando as forças reativas preponderam sobre as forças ativas por esse desvio, elas próprias formam um tipo [...]. Um tipo é, na verdade, uma realidade ao mesmo tempo biológica, psíquica, histórica, social e política (DELEUZE, 1976, p. 95)."
} 
espirito do colonizado. Desse modo, não se constrói linhas de fuga operacionalizando vingança, por mais que a situação colonial convoque para tensões que fazem com que o colonizado tenha sonhos musculares.

A pedagogia "fanoniana" tem o grandioso projeto galvanizador para que aquilo que o autóctone produz no seio do seu próprio solo tenha boa estima e importância, sem que necessidades inventadas espoliem e abram portas para a apropriação dos recursos e da inventividade do povo local. Cabe ressaltar que o rejeite aos valores exógenos, coloniais não é a exacerbação de um sentimento nacionalista e incoerente, mas uma forma de mobilização para a compreensão da situação real do colonizado, em sua dimensão material e psíquica.

Nesse processo, a classe média e os intelectuais precisariam se voltar para os valores do povo, ou seja, se tornaria indispensável o movimento de exercer outro olhar para aqueles aos quais o conhecimento produzido na academia desvaloriza. O exotismo e o estranhamento perderiam lugar para um olhar maduro e responsável, sem recair no abismo do romantismo - lugar perigoso e que reforça estereótipos -, fundando uma nova ética, sob as múltiplas maneiras de resolução de problemas pontuais que ajudam a oxigenar a sociedade em seus períodos de esgotamento de modelos.

No momento em que o colonizado retoma o contato com o seu povo, essa sentinela factícia é pulverizada. Todos os valores mediterrâneos, triunfo da pessoa humana, da clareza do belo, convertem-se em quinquilharias sem vida e sem cor. Todos esses discursos aparecem em agregadores de palavras mortas. Es- ses valores que parecem enobrecer a alma revelam-se inúteis porque não se referem ao combate concreto no qual o povo está engajado. (FANON, 1961 P.35).

Essa é uma interessantíssima passagem, pois ela pressupõe a existência de um campo dinâmico e constante, onde fica bem nítido que o mundo colonial não se entrega, ele se reinventa (mesmo diante de traumas inapagáveis), e, diante disso, ao colonizado não se pode empreender uma pedagogia do esgotamento das necessidades de se engajar na luta, pois "Não esperamos que o colonialismo se suicide. Está na sua lógica defender-se encarniçadamente. Aliás, é a tomada de consciência da sua impossibilidade de sobreviver que determinará a sua liquidação enquanto estilo de contacto com outros povos" (FANON, 1980 p.128).

Fanon está se referindo a momentos específicos dentro da sua trajetória, no contexto da luta de libertação colonial argelina e na experiência colonial na Martinica. Entretanto, não podemos deixar de considerar a atualidade de suas análises, tendo em vista que as tensões produzidas no campo social, no exercício de soberanias disfarçadas em disciplinaridades e normatizações, se reinventam de acordo com as linhas de fuga apresentadas pelos colonizados. Desse modo, algumas investidas agem em resposta ao arrocho do sistema colonial, no entanto, o rizoma está por dentro daquilo que se encaminha como transgressor, fazendo com que nem tudo que seja produzido no seio do povo precarizado, tenha como resultado algo que visa um sentido fechado e direcionado a essa ordem sistêmica, que por sua 
vez reinventa normas, na (re)inserção dessas linhas de fuga aos sistemas disciplinares.

É importante frisar que, segundo Michel Foucault (2010), o estado surge a partir de uma violência perpetrada não somente no front de batalha, mas nas conjecturas e traçados teóricos que visam à dominação. Desse modo, se fez necessário que grupos se organizassem a partir de traços comuns, baseados, em primeiro plano no quesito racial, como justificativa para arregimentar a legitimidade ofensiva. Após dominar os territórios coloniais, seria preciso manter a soberania, mas com aparências democráticas, alheias à dureza das leis, operando por meio do ordenamento jurídico, contudo, disfarçadamente, pois assim os interesses particulares de um poder que se retroalimenta, sujeitando saberes, se autorregulam e criam suas próprias disciplinas.

Nesse sentido, o fluxo educativo Fanoniano é avesso à normalização que se desenha por dentro de grupos fechados em torno do discurso disciplinar, que rejeita a lei, mas age, em última instância, em conformidade com ela, na medida em que criam suas próprias disciplinas sem romper com o ordenamento jurídico oficial, já que eles formam a base do estado. Não seria uma educação maior (Gallo, 2003) a melhor alternativa para o colonizado, isto é, não seria atrelado aos gabinetes de educação, ou com os reguladores das normas, que o povo precarizado operaria transformações, mas sim nos meandros de uma educação menor, que faz o seu rizoma nas micropolíticas cotidianas, olhando para si, em suas dimensões criativas e nos problemas que precisam enfrentar.

\section{Considerações Finais}

O pensamento de Frantz Fanon é complexo e grandioso - não caberia nesta pequena apresentação. Por isso buscamos perseguir somente algumas possibilidades de trazer esse importante pensador negro para o campo das mais intensas disputas sociais, o educacional. Mesmo não tendo sido teórico da educação, Fanon torna possível lançar um olhar mais acurado sobre o que seria um projeto de fato emancipatório, propondo que a sala de aula não se torne mais um receptáculo de grupos que disputam o poder e se travestem com discursos libertários que, em última análise, nada mais quer, senão a subserviência do negro.

A ambiência colonial é desfavorável para o negro, por isso se faz necessário um reordenamento sistêmico, não uma viragem epistêmica, ou a subida de um poder tirânico e despótico que faça vingança contra os descendentes dos seus algozes, mas sim uma nova maneira de empreender as relações sociais, na compreensão da dinâmica histórica de hierarquizações baseadas no critério racial, propondo o seu desmonte. Segundo Fanon, um homem novo precisaria emergir das entranhas do povo, sem responder a estímulos inventados e sem o mínimo de afiliação com os velhos decretos coloniais.

A educação, esteio do povo, precisaria ser radicalmente transformada para que os vícios coloniais abrissem lugar para formas rizomáticas, que toma de empréstimo as experiências positivas para criar, sempre (re)utilizando a potência autóctone como engrenagem principal para bombear os nutrientes necessários para a sobrevivência das sociedades pós-coloniais. Nesse processo, muito ressentimento será aflorado, di- 
versas investidas violentas perpetradas contra os colonizados, incompreensões do próprio oprimido e vários mecanismos opressivos serão empurrados contra a maioria. A linha de fuga é persistir, realizando uma reflexão de si e compreendendo os principais elementos que fazem com que os sistemas funcionem.

O que Fanon deixa de aprendizado para nós, brasileiros, é que a emancipação não acontecerá por meio do erário público, nem tampouco pelas "mãos libertadoras" de senhores e senhoras brancas, proponentes de soluções fáceis e messiânicas. Para Fanon, estaria mais que comprovado que estas formas de conceber a luta pela libertação das amarras coloniais, não passariam de transferência de poder; exemplo disso é a independência do Brasil. O melhor caminho a ser percorrido seria, portanto, o rejeite de forças alienígenas que reificam as formas de organizações sociais autóctones.

O ganho qualitativo se daria no levante da estima do colonizado, que na complexidade rizomática do seu próprio cotidiano, seria in-trans-formado sobre novos conhecimentos possíveis / disponíveis que o conduzirá para outra dimensão, fora das amarras coloniais, e distante do perigo do ressentimento de se enclausurar nos guetos das forças reativas, que nada realiza e essencializa tudo aquilo que não dialoga com as suas crenças. Uma educação Fanoniana é uma educação rizomática, onde o tempo atua em várias dimensões, não capturáveis pela dinâmica avassaladora das imposições coloniais.

Portanto, lançamos o desafio de pensar os fluxos educativos a partir da filosofia de Frantz Fanon, empreitada jamais ensaiada por pesquisadores brasileiros. Trouxemos outros pensadores de grande envergadura e importância no cenário internacional, a fim de elevar a ainda mais o pensamento de martinicano. Ao fazer isso, assumimos o risco de críticas e olhares reacionários, que encaram com estranheza um trabalho dessa natureza, que não se limita a se fechar em correntes de pensamentos, entendendo que o momento requer inovação. Por fim, reafirmamos que o grande potencial revolucionário não está na velha ideia de proletariado, mas sim no povo das ruas, precarizados nas favelas pelos estilhaços coloniais, pois, conforme Fanon, são esses que ainda carregam os germes ancestrais capazes de transformar a realidade universal, tamanha a sua força e plenitude.

\section{Referências}

BERGSON, Henri. A Evolução Criadora. São Paulo: Editora UNESP, 2009.

DELEUZE, Gilles. Diferença e Repetição. São Paulo: Graal, 2009. , Gilles. Nietzsche e a Filosofia. Rio de Janeiro: Editora Rio, 1976.

DELEUZE, Gilles e GUATTARI, Félix. O Anti-Édipo. São Paulo: Editora 34, 2010. 
, O Que é a Filosofia? São Paulo: Editora 34, 2010.

, Mil Platôs: Capitalismo e Esquizofrenia II Volume I. São Paulo: Editora 34,

2014.

FANON, Frantz. Os Condenados da Terra. Rio de Janeiro: Civilização Brasileira, 1961.

Frantz. Pele Negra, Máscaras Brancas. Salvador: EDUFBA, 2008.

Em Defesa da Revolução Africana. Lisboa: Livraria Sá da Costa Editora, 1980.

GALLO, Silvio. Deleuze e Educação. Rio de Janeiro: Autêntica, 2003.

FOUCAULT, Michel. Em Defesa da Sociedade. São Paulo: Martins Fontes, 2010.

RAMOS, Guerreiro. Introdução Crítica à Sociologia Brasileira. Rio de Janeiro: Editorial Andes limitada, 1957.

RAMOSE, Mogobe. Globalização e Ubuntu. In: MENESES, Maria Paula e; SANTOS, Boaventura de Sousa (Orgs.). Epistemologias do Sul. São Paulo: Cortez. 2010.

Recebido em: $14 / 07 / 2017$

Aprovado em: 31/10/2019 